This is an author produced version of a paper published in Intensive Care Medicine. This paper has been peer-reviewed but does not include the final publisher proof-corrections or journal pagination.

Citation for the published paper:

Samuelson, Karin and Lundberg, Dag and Fridlund, Bengt.

"Memory in relation to depth of sedation in adult mechanically ventilated intensive care patients"

Intensive Care Medicine, 2006, Issue: Mar 7.

http://dx.doi.org/10.1007/s00134-006-0105-x

Access to the published version may require journal subscription.

Published with permission from: Springer 


\section{Memory in relation to depth of sedation in adult mechanically ventilated intensive care patients}

Karin A. M. Samuelson, Dag Lundberg, Bengt Fridlund

K. A. M. Samuelson, Division of Nursing, Department of Health Sciences, Lund University, P.O. Box 157, SE-221 00 Lund, Sweden. E-mail: Karin.Samuelson@med.lu.se Tel: +46 462221875 Fax: +46 462221935

D. Lundberg, Division of Anaesthesiology and Intensive Care, Department of Clinical Sciences, Lund University Hospital, SE-22185 Lund, Sweden

B. Fridlund, Division of Nursing, Department of Health Sciences, Lund University, P.O. Box 157, SE-221 00 Lund, Sweden 


\section{Abstract}

Objective: To investigate the relationship between memory and intensive care sedation.

Design and setting: Prospective cohort study over 18 months in two general intensive care units (ICUs) in district university hospitals.

Patients: 313 intubated mechanically ventilated adults admitted for more than 24 hours, 250 of whom completed the study.

Measurements: Patients $(\mathrm{n}=250)$ were interviewed at ward 5 days after discharge from the ICU with support of the ICU Memory Tool. Patient characteristics, doses of sedative and analgesic agents, and sedation scores as measured by the Motor Activity Assessment Scale (MAAS) were collected from hospital records after the interview.

Results: Patients with no recall (18\%) were significantly older, had higher baseline severity of illness, and fewer periods of wakefulness (median proportion of MAAS score 3; 0.37 vs 0.70 , $p<0.0001)$, than those who had memories of the ICU (82\%). Multivariate analyses showed that increasing proportion of MAAS 0-2 and older age were significantly associated with having no recall. Patients with delusional memories (34\%) had significantly longer ICU stay (md 6.6 vs 2,2 days, $p<0.0001$ ), higher baseline severity of illness, higher proportions of MAAS scores 4-6 and more administration of midazolam, than those with recall of the ICU without delusional memories.

Conclusions: This study suggests that heavy sedation increases the risk of having no recall, and longer ICU stay increases the risk of delusional memories. The depth of sedation during total ICU as recorded with the MAAS may predict the probability of having memories of the ICU.

Keywords: Sedation, Intensive care unit, Mechanical ventilation, Recall, Delusions, Nursing 


\section{Introduction}

Critically ill patients' experiences of being in intensive care vary from having no memories to recalling factual events, feelings and delusional memories $[1,2]$. From the patient's perspective, having either no recall or unpleasant memories and delusional memories, can be very disturbing and may affect the rehabilitation process and the sense of well-being $[3,4,5$, 6]. In the long-term, experiences of discomfort and stressful memories in the intensive care unit (ICU) have been associated with the development of acute posttraumatic stress disorder related symptoms, anxiety, depression, and impaired health-related quality of life $[7,8,9,10$, $11]$.

The use of sedatives and/or analgesics (SAAs) is important for ensuring comfort, especially in patients mechanically ventilated due to the discomfort caused by the endotracheal tube and the respiratory therapy [12]. Adapted to the individual needs and the current situation, adequate administration of SAAs increases comfort, reduces stress response and facilitates diagnostic and therapeutic procedures $[13,14]$. Although there are numerous reasons for disturbed memory and amnesia in critically ill patients $[15,16,17]$, the amnestic properties of SAAs make the impact on memory evident [18]. A dose-dependent responsiveness has been suggested between commonly administered sedatives in the ICU and the formation and retention of memory $[19,20]$. Recent studies focusing on the relationship between SAAs and memory of the ICU have included measures of days and amount of sedation [21, 22]. Because of the unpredictable variation in critically ill patients' response to SAAs [23], the depth of sedation is important and may have an impact on patients' recall of the intensive care stay [24]. The aim of this study was therefore to investigate the relationship between memory and 
intensive care sedation in mechanically ventilated ICU patients and to examine whether more heavily sedated would have less recall and increased delusional memories of the ICU.

\section{Material and methods}

Design, setting and routines

This prospective cohort study was carried out over 18 months beginning in September 2003 in two general ICUs, with seven and ten beds respectively, at two Swedish university hospitals. The study was approved by the Ethics Committee at Lund University, Sweden. The sedation guidelines used in the two ICUs were developed in collaboration, inspired by the protocol used by Brook and colleagues [25] and included sedation goals and nursing management of sedation during mechanical ventilation.

In general, propofol was used for short-term sedation, and for long-term sedation a relay with midazolam was commonly practiced. Opioids were always administered in conjunction with sedatives. The sedation goal (i.e. MAAS 2-3, except for cases requiring heavy sedation as part of their medical therapy) was reassessed on a daily basis along with attempts to decrease the doses of SAAs. When neuromuscular blocking agents were administered, heavy sedation was used together with train-of-four measurements. After long-term sedation during weaning, clonodine was commonly administered. Daily interruption of sedation was not practiced [26]. The nurse-to-patient ratio was 1:1-2 and nurses administered the amount of medication judged necessary to maintain the patient within the targeted sedation score. Patients were not physically restrained and never left alone. 
Sample and criteria

All 596 admitted patients were eligible for enrollment in the study who were aged 18 years or more, had been intubated, received mechanical ventilation and stayed in one of the two ICUs for more than 24 hours. Exclusion criteria were: head injury, intoxication, suicide attempt, psychotic illness, mental retardation, hearing or talking disability, non-Swedish-speaking, transference to other hospital or mechanical ventilation at discharge. The number of patients included in study was 313, 63 of whom were lost to follow-up (Figure 1). These excluded patients ( $\mathrm{n}=63)$ were significantly older, had higher baseline Acute Physiology and Chronic Health Evaluation (APACHE) II score, longer ventilation time and ICU stay and included more emergency admissions, but there was no significant differences in the use of SAAs or depth of sedation. The 250 patients who were included (mean age 63.4 years, range 19-96; $51.2 \%$ men) had a median APACHE II score on admission of 18 (range 2-49) and included 82.4\% emergency admissions. Admission diagnostic categories in ICU included primary medical reason in $45 \%$ (pulmonary $20 \%$, cardiac $12 \%$, gastric $8 \%$ and other $4 \%$ ), postoperative complications or major surgery in $47 \%$ (abdominal $22 \%$, cardiothoracic $14 \%$ and other $11 \%$ ) and multiple trauma in $8 \%$. The median duration of mechanical ventilation was 1.4 days (range 0.02-34) and the median length of ICU stay was 3.4 days (range 1-37).

Instruments

Severity of illness was measured by APACHE II [27] was used. The Motor Activity Assessment Scale (MAAS) is a seven-point sedation scale ranging from 0 (unresponsive) to 6 
(dangerously agitated) [28]. A score of 3 indicates that the patient is awake, calm and cooperative. When tested for interrater reliability in the two ICUs, the weighted $\kappa$ value for 50 in-pair assessments was 0.84 (unpublished data). The ICU Memory Tool (ICUM) consists of 14 items that assess patients' memory of the intensive care experience [29]. Validation of the Swedish version using both open-ended questions and the ICUM tool in 20 thoracic ICU patients showed good overall agreement (unpublished data). This study concerned item $4 \mathrm{~b}$, "What do you remember?" providing a checklist of 11 factual events, six feelings and four delusional memories. If one or more items on the checklist were recalled this was defined as having memories of the ICU. No recall was defined as complete absence of any experience (complete amnesia). Patients describing nightmares, hallucinations or paranoid delusions while in the ICU or such memories after discharge were defined as having delusional memories [29], excluding patients describing their dreams as "ordinary" and patients with hallucinations at ward due to epidural opioids. The Confusion Assessment Method for the ICU (CAM-ICU) evaluates the presence or absence of delirium [30]. Before the study, all the instruments were translated into Swedish and back-translated by a native English-speaking interpreter. Case selection and data collection procedures were piloted in 14 ICU patients (not included in the study).

Data collection

Nurses in the ICUs were instructed to assess and document each patient's level of sedation every $4 \mathrm{~h}$ using the MAAS. When patients received a neuromuscular blocking agent in conjunction with heavy sedation, score 0 was registered. All patients discharged from the ICUs were checked for eligibility every third day by first author. The included patients were 
visited at the ward 3-5 days after ICU discharge. Absence of delirium and inattention were checked by using the CAM-ICU, and if medically impaired or confused, patients were revisited 3-5 days later. After written informed consent was obtained, patients were interviewed face to face by the first author using the ICUM. Patient data were recorded from hospital records after the interview. Demographic characteristics, medical history, diagnoses, reason for ICU admission, baseline severity of illness, length of ICU stay, mechanical ventilation and daily doses of SAAs administered intravenously (IV), and all MAAS scores were recorded. Data were collected as one continuous ICU stay for patients readmitted in less than 5 days and for patients transferred between the two ICUs. If readmitted after 5 days from discharge only the first admission was recorded.

\section{Statistics}

A sample size of 250 was estimated to provide $85 \%$ power with $p<0.05$ to detect a difference of $25 \%$ for unequal groups. For the purpose of this study, proportions of MAAS scores $0-2,3$ and 4-6 were calculated for each patient for different time periods. For example, score 3 for ventilation period were counted and divided by the total number of scores for this period. If fewer than four values per day were recorded, values were regarded as missing essentially at random for reasons not related to the study. Analyses were performed both with and without the 26 patients with missing MAAS scores, detecting no significant differences in results. Chi-squared tests with continuity correction, or Fisher's exact test when appropriate, were used to compare categorical variables. For comparing numerical data the Student's $t$ test was used for normally distributed data, and the Mann-Whitney $U$ test for skewed data [31]. 
Logistic regression analyses (backward stepwise method, likelihood ratio) were performed with no recall and delusional memories as dependent variables. Theoretically important variables were entered in models (see table 4). Due to multicollinearity the variables of length of ventilation and of sedation and average and cumulative doses of SAAs were not entered. The models were developed using data from one ICU and validated on data from other ICU [32]. Data were computerised and analysed using SPSS for Windows (version 11.5 Chicago, USA). Statistical significance was set at $p<0.05$.

\section{Results}

Intensive care sedation

All patients interviewed received SAAs intravenoulsy and sedative agents were administered by continuous intravenous infusions in $97 \%$ of patients, opioids in $88 \%$. Propofol was received by $94 \%$ of patients, midazolam $32 \%$, ketobemidon (opioid) $83 \%$, fentanyl $15 \%$, morphine $11 \%$ and epidural opioids in $11 \%$. Neuromuscular blocking agents were used in $11 \%$ of patients. The median proportion of MAAS score 3 was 0.39 for the ventilation period, 1.0 for the non-ventilation period and 0.67 for the total ICU stay (Table 1). Proportions of different sedation scores were significantly associated with average daily doses of propofol and midazolam (Table 2).

Memory 
Of the 250 patients interviewed, $82 \%(n=206)$ reported memories of the ICU. There was no significant differences in prevalence of memories in patients interviewed by the first visit versus those interviewed later $(83 \%$ vs. $78 \%, p=0.153)$, or between the two ICUs, or in patients who had read their patient diaries before the interview $(n=9)$ vs. to others. Among patients with memories, $96 \%$ had factual recall with a median of seven 7 events remembered (range $0-11$ ), 88\% memories of feelings (median 2, range $0-6$ ) and $41 \%$ delusional memories (median 0, range 0-4). Patients with no recall were significantly older, had higher APACHE II score on admission and higher proportion of MAAS scores of $0-2$, than those with memories of the ICU (Table 3). Concerning the use of SAAs no significant differences in total cumulative or average daily doses or in length of sedation were detected between groups or in the patients $(n=180)$ receiving only one type of sedative drug during ICU stay. The multivariate analyses showed that increasing proportion of MAAS 0-2 scores and older age were significantly associated with having no recall (Table 4). Inspection of odds ratios with proportions of MAAS 0-2 categorized according to quartiles (first quartile as reference category), indicated no significant increased risk of having no recall in the second and third quartiles, whereas the fourth quartile (proportions $>0.44$ ) was significantly associated with a tenfold increase in risk. Patients with recall remembering the endotracheal tube $(n=116)$ had a significantly higher proportion of MAAS score 3 during ventilation period than those not remembering the tube (md 0.56 vs. $0.18, p<0.0001$ ), without significant differences in doses of SAAs.

Delusional memories 
Among patients with delusional memories $(\mathrm{n}=85), 61 \%$ reported nightmares, $59 \%$ hallucinations, and 16\% paranoid delusions. These patients had significantly higher APACHE II scores, longer ICU stay (median 6.6 vs. 2.2 days, $p<0.0001$ ) including longer duration of mechanical ventilation and higher cumulative doses of SAAs, more MAAS scores 4-6 (median proportions 0.04 vs. $0.00, p=0.041$ ) and more received midazolam than among patients with recall without delusional memories $(\mathrm{n}=121$; Table 5). The multivariate model showed that longer ICU stay, younger age and higher APACHE II scores was significantly associated with having delusional memories of the ICU (Table 4). Among patients with paranoid delusions proportions of MAAS 0-2 and 4-6 were higher than in those with recall without paranoid delusions (median 0.37 vs. $0.24, p=0.034$; median 0.12 vs. $0.00 p=0.001$ ), and the association with MAAS 4-6 was confirmed by multivariate analyses (Table 4). In patients with delusional memories without factual recall $(n=8)$ the proportion of MAAS $0-2$ scores was higher (median 0.57 vs. $0.24, p=0.006$ ) and the ICU stay the longest (median 12.8 vs. 3.4 days, $p=0.001$ ) than in others, and the associations were confirmed by multivariate analyses (Table 4). Patients receiving neuromuscular blocking agents $(n=28)$ did not have higher prevalence of delusional memories than others ( $32 \%$ vs $34 \%, p=0.993)$. The patients with recall ventilated more than $48 \mathrm{~h}(\mathrm{n}=86)$ had significantly higher APACHE scores than those ventilated less $(n=120)$; more received midazolam, more were primary medical patients and the prevalence of delusional memories was higher (62\% vs. $27 \%, p<0.0001)$. 


\section{Discussion}

In this study having no recall of the ICU was reported by $18 \%$ of patients, compared to 30 $40 \%$ in previous recent studies with large samples [10, 12, 21, 33]. According to this study patients with no recall were more heavily sedated, as measured by sedation scores, than patients with memories of the ICU, which has not been shown in previous studies concerning memory and sedation $[21,22]$. The independent relationship was demonstrated by the multivariable analyses, showing a $60 \%$ increase in risk of having no recall, for a 0.1 increase in proportion of MAAS 0-2 scores and a steeper increase in risk for proportions higher than 0.44. As indicated in this study, the depth of sedation is not solely affected by doses of SAAs, but of numerous factors. Bion et al. [34] demonstrated long ago that increasing severity of illness, as measured by APACHE II, depresses the level of consciousness more than different doses of morphine, measured as levels of morphine in blood. Adding the confound factors of accumulation, interaction, tolerance and weaning from SAAs, the dose-response effect is most difficult to predict in ICU patients [23]. This strongly emphasizes that sedation requirements are individual and that assessment of depth of sedation by means of a sedation score is essential and still the best method available for evaluating sedation in critically ill patients $[35,36,37]$.

Previous studies have reported that $46-75 \%$ of the patients experienced delusional memories $[1,7,10,38]$, compared to $34 \%$ in the present study. In this study a longer stay in the ICU was significantly associated with the occurrence of delusional memories (Tables 4, 5). This result is in line with a previous study in which long-term critically ill patients seemed at greater risk of developing delusional memories [22]. The role of SAAs can be discussed; 
inevitably, longer ICU stay including longer duration of mechanical ventilation entails higher cumulative doses of SAAs. On the other hand it is suggested that the use of SAAs affects the duration of ventilation and thus length of ICU stay [26, 39] and in particular the use of midazolam for long-term sedation in this study may have influenced the awakening and time to extubation [36]. According to the findings in this study, patients with delusional memories were not more heavily sedated than others, since the proportion of sedation scores $0-2$ was almost identical in the two groups (Table 5). However, patients with paranoid delusions and especially those with delusional memories without factual recall seemed to be more heavily sedated than others, and the role of SAAs including midazolam needs to be further explored. Patients with delusional memories showed more signs of agitation by means of MAAS scores 4-6. It is an obvious clinical finding that long-term critically ill patients are at risk for acute withdrawal syndromes during drug weaning [40]. Furthermore, it is easy to imagine that agitation follows the anxiety, confusion and horror content in delusional memories. This finding suggests that until we fully understand the rationale of delusional memories, it is reasonable to make efforts to reduce the length of stay in the ICU, reinforce sympathetic handling and reassurance of patients and includ early follow-up as a standard routine in critically ill patients.

The subjective nature of memory experiences makes the accuracy of patients' recall difficult to assess. Some memories may have been lost before the interview took place and others may emerge only later, and information provided by relatives and staff may influence patients' recollections. The clinical sedation scale MAAS used in this study is a subjective measure based on estimates provided by different nurses at fixed intervals. It does not detect subtle changes in depth of sedation or capture fluctuations between assessments. Notwithstanding 
these limitations the MAAS is a valid and reliable scale detecting major changes in level of sedation [28] and the analysis of proportions of different MAAS scores should therefore provide an overall picture of patients' depth of sedation during the ICU stay.

For the purpose of external validity, data from patients excluded from study were compared with those included. Patients excluded had significantly higher baseline APACHE II score, longer duration of ventilation, and were more heavily sedated as measured by doses of SAAs and sedation scores. Also, significantly more were men and emergency admissions. Disparities in survival rate, diagnoses and respiratory function at discharge for excluded patients might explain some of the differences. This suggests that the results of this study should be generalized only to mechanically ventilated survivors with more than $24 \mathrm{~h}$ stay in general ICUs with similar use of SAAs, and who are extubated and reasonably awake before discharge.

As hypothesized, the findings of this study suggest that heavy sedation increases the risk of having no recall, but the increase in risk of delusional memories in general could not be confirmed. However, the findings suggest that long-term heavy sedation increases the risk of having delusional memories without factual recall. According to our findings, there is a greater risk of delusional memories in long-term critically ill patients and the depth of sedation recorded with the MAAS may predict the probability of having memories of the ICU. Due to limitations in study design and measurement quality, further research, preferably as randomized clinical trials, is necessary to confirm associations suggested in this study. Patients' perceptions of stressful experiences and long-tem psychological outcomes in relation to intensive care sedation need to be explored. 


\section{References}

1. Capuzzo M, Valpondi V, Cingolani E, De Luca S, Gianstefani G, Grassi L, Alvisi R (2004) Application of the Italian version of the intensive care unit Memory tool in the clinical setting. Crit Care 8:R48-55

2. Leur JP van de, van der Schans CP, Loef BG, Deelman BG, Geertzen JH, Zwaveling JH (2004) Discomfort and factual recollection in intensive care unit patients. Crit Care 8:R467R473

3. Griffiths RD, Jones C (2001) Filling the intensive care memory gap? Intensive Care Med 27:344-346

4. Jones C (2002) Acute psychological problems. In: Griffiths RD, Jones C (ed) Intensive care aftercare. Butterworth-Heinemann, Oxford, pp 19-26

5. Skirrow P (2002) Delusional memories of ICU. In: Griffiths RD, Jones C (ed) Intensive care aftercare. Butterworth-Heinemann, Oxford, pp 28-35

6. Hupcey JE, Zimmerman HE (2000) The need to know: experiences of critically ill patients. Am J Crit Care 9:192-198

7. Jones C, Griffiths RD, Humphris G, Skirrow PM (2001) Memory, delusions, and the development of acute posttraumatic stress disorder-related symptoms after intensive care. Crit Care Med 29:573-580

8. Rattray J, Johnston M, Wildsmith JA (2005) Predictors of emotional outcomes of intensive care. Anaesthesia 60:1085-1092

9. Schelling G, Stoll C, Haller M, Briegel J, Manert W, Hummel T, Lenhart A, Heyduck M, Polasek J, Meier M, Preuss U, Bullinger M, Schuffel W, Peter K (1998) Health-related quality of life and posttraumatic stress disorder in survivors of the acute respiratory distress syndrome. Crit Care Med 26:651-659

10. Granja C, Lopes A, Moreira S, Dias C, Costa-Pereira A, Carneiro A (2005) Patients' recollections of experiences in the intensive care unit may affect their quality of life. Crit Care 9:R96-R109

11. Hough CL, Curtis JR (2005) Long-term sequelae of critical illness: memories and healthrelated quality of life. Crit Care 9:145-146

12. Rotondi AJ, Chelluri L, Sirio C, Mendelsohn A, Schulz R, Belle S, Im K, Donahoe M, Pinsky MR (2002) Patients' recollections of stressful experiences while receiving prolonged mechanical ventilation in an intensive care unit. Crit Care Med 30:746-752

13. Burchardi H (2004) Aims of sedation/analgesia. Minerva Anestesiol 70:137-143

14. Walder B, Tramer MR (2004) Analgesia and sedation in critically ill patients. Swiss Med Wkly 134:333-346

15. Jones C, Griffiths RD, Humphris G (2000) Disturbed memory and amnesia related to intensive care. Memory 8:79-94

16. McGaugh JL, Cahill L (1997) Interaction of neuromodulatory systems in modulating memory storage. Behav Brain Res 83:31-38 
17. Kolk BA van der (1996) Trauma and memory. In: McFarlane AC, van der Kolk BA, Weisaeth L (ed) Traumatic stress: the effects of overwhelming experience on mind, body, and society. Guilford, New York, pp 279-302

18. Wagner BK, O'Hara DA, Hammond JS (1997) Drugs for amnesia in the ICU. Am J Crit Care 6:192-201

19. Clifford JO, Buchman TG (2002) Sedation modulates recognition of novel stimuli and adaptation to regular stimuli in critically ill adults. Crit Care Med 30:609-616

20. Veselis RA, Reinsel RA, Feshchenko VA, Johnson R (2004) Information loss over time defines the memory defect of propofol: a comparative response with thiopental and dexmedetomidine. Anesthesiology 101:831-841

21. Capuzzo M, Pinamonti A, Cingolani E, Grassi L, Bianconi M, Contu P, Gritti G, Alvisi R (2001) Analgesia, sedation, and memory of intensive care. J Crit Care 16:83-89

22. Rundshagen I, Schnabel K, Wegner C, Schulte am Esch S (2002) Incidence of recall, nightmares, and hallucinations during analgosedation in intensive care. Intensive Care Med 28:38-43

23. Young C, Knudsen N, Hilton A, Reves JG (2000) Sedation in the intensive care unit. Crit Care Med 28:854-866

24. Samuelson KA, Lundberg D, Fridlund B (2005). Memory in relation to intensive care sedation. Intensive Care Med 31 (suppl 1):S12

25. Brook AD, Ahrens TS, Schaiff R, Prentice D, Sherman G, Shannon W, Kollef MH (1999) Effect of a nursing-implemented sedation protocol on the duration of mechanical ventilation. Crit Care Med 27:2609-2615

26. Kress JP, Pohlman AS, O'Connor MF, Hall JB (2000) Daily interruption of sedative infusions in critically ill patients undergoing mechanical ventilation. N Engl J Med 342:1471-1477

27. Knaus WA, Draper EA, Wagner DP, Zimmerman JE (1985) APACHE II: a severity of disease classification system. Crit Care Med 13:818-829

28. Devlin JW, Boleski G, Mlynarek M, Nerenz DR, Peterson E, Jankowski M, Horst HM, Zarowitz BJ (1999) Motor Activity Assessment Scale: a valid and reliable sedation scale for use with mechanically ventilated patients in an adult surgical intensive care unit. Crit Care Med 27:1271-1275

29. Jones C, Humphris G, Griffiths R (2000) Preliminary validation of the ICUM tool: a tool for assessing memory of the intensive care experience. Clin Intensive Care 11:251-255

30. Ely EW, Inouye SK, Bernard GR, Gordon S, Francis J, May L, Truman B, Speroff T, Gautam S, Margolin R, Hart RP, Dittus R (2001) Delirium in mechanically ventilated patients: validity and reliability of the Confusion Assessment Method for the intensive care unit (CAM-ICU). JAMA 286:2703-2710

31. Altman DG (1991) Practical statistics for medical research. Chapman and Hall, London

32. Hosmer DW, Lemeshow S (2000) Applied logistic regression. Wiley, New York

33. Russell S (1999) An exploratory study of patients' perceptions, memories and experiences of an intensive care unit. J Adv Nurs 29:783-791

34. Bion, JF, Logan BK, Newman PM, Brodie MJ, Oliver JS, Aitchison TC, Ledingham IM (1986) Sedation in intensive care: morphine and renal function. Intensive Care Med 12:359365

35. Devlin JW, Fraser GL, Kanji S, Riker RR (2001) Sedation assessment in critically ill adults. Ann Pharmacother 35:1624-1632

36. Jacobi J, Fraser GL, Coursin DB, Riker RR, Fontaine D, Wittbrodt ET, Chalfin DB, Masica MF, Bjerke HS, Coplin WM, Crippen DW, Fuchs BD, Kelleher RM, Marik PE, Nasraway 
SA, Murray MJ, Peruzzi WT, Lumb PD (2002) Clinical practice guidelines for the sustained use of sedatives and analgesics in the critically ill adult. Crit Care Med 30:119-141

37. Watson BD, Kane-Gill SL (2004) Sedation assessment in critically ill adults: 2001-2004 update. Ann Pharmacother 38:1898-1906

38. Roberts B, Chaboyer W (2004) Patients' dreams and unreal experiences following intensive care unit admission. Nurs Crit Care 9:173-180

39. Kollef MH, Levy NT, Ahrens TS, Schaiff R, Prentice D, Sherman G (1998) The use of continuous i.v. sedation is associated with prolongation of mechanical ventilation. Chest 114:541-548

40. Cammarano WB, Pittet JF, Weitz S, Schlobohm RM, Marks JD (1998). Acute withdrawal syndrome related to the administration of analgesic and sedative medications in adult intensive care unit patients. Crit Care Med 26: 676-684 


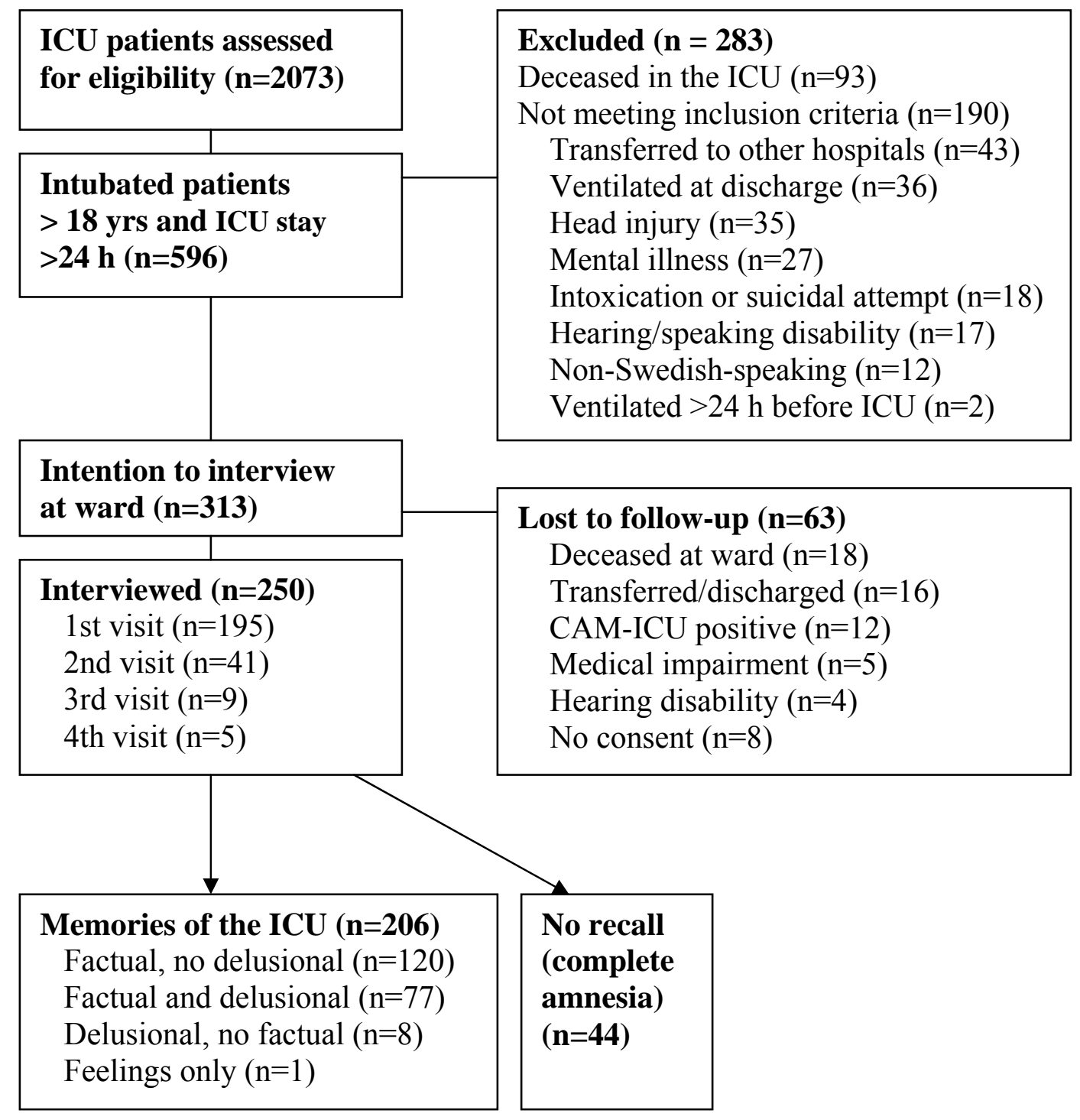

Figure 1 Flowchart of mechanically ventilated patients. ICU=intensive care unit, $C A M-$ $I C U=$ confusion assessment method for the ICU. 
Table 1 Proportions of sedation scores for different time periods in mechanically ventilated patients interviewed $(\mathrm{n}=250)(M A A S=$ motor activity assessment scale, $m d=$ median, $I Q R=$ interquartile range)

\begin{tabular}{llll}
\hline & Ventilation period & $\begin{array}{l}\text { Non-ventilation } \\
\text { period }\end{array}$ & Total ICU stay \\
\hline MAAS 0-2, md proportion (IQR) & $0.50(0.56)$ & $0.0(0.03)$ & $0.27(0.30)$ \\
MAAS 3, md proportion (IQR) & $0.39(0.58)$ & $1.0(0.19)$ & $0.67(0.38)$ \\
MAAS 4-6, md proportion (IQR) & $0.0(0.05)$ & $0.0(0.10)$ & $0.0(0.10)$ \\
Sum, number of values recorded & 4417 & 2658 & 7075 \\
\hline
\end{tabular}


Table 2 Correlations (Spearman's $r$ ) between characteristics of mechanically ventilated patients $(\mathrm{n}=250)$ and proportions of different sedation scores for total ICU stay (ICU=intensive care unit, $M A A S=$ motor activity assessment scale, $A P A C H E=$ acute physiology and chronic health evaluation)

\begin{tabular}{|c|c|c|c|c|c|c|}
\hline & \multicolumn{2}{|c|}{ MAAS 0-2 } & \multicolumn{2}{|l|}{ MAAS 3} & \multicolumn{2}{|c|}{ MAAS 4-6 } \\
\hline & $r$ & $p$ & $r$ & $p$ & $r$ & $p$ \\
\hline APACHE II score & 0.28 & $<0.0001$ & -0.32 & $<0.0001$ & 0.20 & 0.001 \\
\hline Days of ICU stay & 0.17 & 0.009 & -0.23 & $<0.0001$ & 0.35 & $<0.0001$ \\
\hline Days of ventilation & 0.36 & $<0.0001$ & -0.38 & $<0.0001$ & 0.29 & $<0.0001$ \\
\hline Days of continuous & & & & & & \\
\hline i.v. sedation & 0.39 & $<0.0001$ & -0.44 & $<0.0001$ & 0.38 & $<0.0001$ \\
\hline Propofol* $(n=171)$ & & & & & & \\
\hline Avarage daily dose & 0.59 & $<0.0001$ & -0.59 & $<0.0001$ & 0.21 & 0.006 \\
\hline Midazolam* (n=9) & & & & & & \\
\hline Avarage daily dose & 0.82 & 0.007 & -0.83 & 0.005 & 0.55 & 0.127 \\
\hline
\end{tabular}

*Correlations performed for the number of patients receiving only propofol or midazolam as sedative agent. 
Table 3 Characteristics in mechanically ventilated patients with and without memories of the intensive care unit $(\mathrm{n}=250)(\mathrm{SD}=$ standard deviation, $\mathrm{ICU}=$ intensive care unit, $\mathrm{md}=$ median, $\mathrm{IQR}=$ interquartile range, $\mathrm{APACHE}=$ acute physiology and chronic health evaluation, $\mathrm{MAAS}=$ motor activity assessment scale)

\begin{tabular}{llll}
\hline & $\begin{array}{l}\text { Memories } \\
(\mathrm{n}=206)\end{array}$ & $\begin{array}{l}\text { No memory* } \\
(\mathrm{n}=44)\end{array}$ & $p$ value \\
\hline Age, mean (SD), years & $62.3(13.7)$ & $68.5(13.5)$ & $\mathbf{0 . 0 0 6}$ \\
Male sex, \% & 49.0 & 61.4 & 0.187 \\
ICU admission emergent, \% & 82.0 & 84.1 & 0.915 \\
Admission category & & & 0.180 \\
$\quad$ Primary medical, \% & 42.2 & 56.8 & \\
$\quad$ Postop complications/major surgery, \% & 48.5 & 38.6 & \\
$\quad$ Trauma, \% & 9.2 & 4.5 & \\
APACHE II, md (IQR), score & $17.0(11.0)$ & $21.0(13.8)$ & $\mathbf{0 . 0 0 5}$ \\
ICU stay, md (IQR), days & $3.60(5.22)$ & $2.86(2.54)$ & 0.094 \\
Mechanical ventilation, md (IQR), days & $1.33(3.86)$ & $1.77(2.17)$ & 0.918 \\
Sedation scores for total ICU stay & & & \\
$\quad$ MAAS 0-2, md (IQR), proportion & $0.25(0.26)$ & $0.50(0.43)$ & $<\mathbf{0 . 0 0 0 1}$ \\
$\quad$ MAAS 3, md (IQR), proportion & $0.70(0.32)$ & $0.37(0.43)$ & $<\mathbf{0 . 0 0 0 1}$ \\
$\quad$ MAAS 4-6, md (IQR), proportion & $0.0(0.10)$ & $0.0(0.13)$ & 0.587 \\
Average daily dose & & & \\
$\quad$ Propofol, md (IQR), mg/kg/day & $7.98(16.2)$ & $8.12(12.2)$ & 0.262 \\
$\quad$ Midazolam, md (IQR), mg/kg/day & $0.00(0.03)$ & $0.00(0.04)$ & 0.579 \\
\hline
\end{tabular}

*No memory=complete amnesia (with no delusional memories) 
Table 4 Multivariate analyses (logistic regression) of factors associated with no recall (complete amnesia) and delusional memories of the ICU, in mechanically ventilated patients. Covariates entered: age (years), sex, admission (emergent or elective), diagnose category (medical, surgical, trauma), severity of illness (scores), length of ICU (days), midazolam received (yes or no), MAAS scores 0-2 and 4-6 for total ICU stay (proportions) (ICU=intensive care unit, MAAS=motor activity assessment scale, $\mathrm{OR}=$ estimated odds ratio, $\mathrm{CI}=$ confidence interval, $\mathrm{LR}=$ likelihood ratio)

\begin{tabular}{|c|c|c|c|c|}
\hline & OR & $95 \% \mathrm{CI}$ & $p$ value & LR-test \\
\hline \multicolumn{5}{|c|}{ Amnesia $($ yes $=44$, no=206) } \\
\hline MAAS scores $0-2$ & $1.60^{*}$ & $1.35-1.91$ & $<0.0001$ & 34.1 \\
\hline Age & 1.04 & $1.01-1.07$ & 0.005 & 7.95 \\
\hline \multicolumn{5}{|c|}{ Delusional memories $(\mathrm{yes}=85, \mathrm{no}=121)$} \\
\hline ICU stay & 1.17 & $1.09-1.25$ & $<0.0001$ & 27.2 \\
\hline APACHE II & 1.05 & $1.01-1.10$ & 0.016 & 5.83 \\
\hline Age & 0.97 & $0.95-0.99$ & 0.035 & 4.46 \\
\hline \multicolumn{5}{|c|}{ Paranoid delusions $(\mathrm{yes}=14, \mathrm{no}=192)$} \\
\hline MAAS scores 4-6 & $2.90^{*}$ & $1.64-5.11$ & $<0.0001$ & 15.0 \\
\hline ICU length of stay & 1.16 & $1.06-1.26$ & 0.001 & 10.6 \\
\hline Age, years & 0.93 & $0.88-0.99$ & 0.011 & 6.51 \\
\hline \multicolumn{5}{|c|}{ No factual, only delusional $(\mathrm{yes}=8, \mathrm{no}=198)$} \\
\hline MAAS scores $0-2$ & $1.76^{*}$ & $1.14-2.72$ & 0.008 & 7.00 \\
\hline ICU length of stay & 1.12 & $1.03-1.21$ & 0.006 & 7.53 \\
\hline
\end{tabular}

*Oddsratio for a 0.1 increase in proportion of MAAS scores. 
Table 5 Comparison of characteristics in patients with and without delusional memories, for mechanically ventilated patients with recall of the intensive care unit $(n=206)(I C U=$ intensive care unit, $\mathrm{SD}=$ standard deviation, $\mathrm{md}=$ median, $\mathrm{IQR}=$ interquartile range, $\mathrm{APACHE}=$ acute physiology and chronic health evaluation, MAAS=motor activity assessment scale)

\begin{tabular}{|c|c|c|c|}
\hline & $\begin{array}{l}\text { Delusional } \\
\text { memories } \\
(\mathrm{n}=85)\end{array}$ & $\begin{array}{l}\text { No delusional } \\
\text { memories } \\
(\mathrm{n}=121)\end{array}$ & $p$ value \\
\hline Age, mean (SD), years & $60.8(15.0)$ & $63.3(12.5)$ & 0.197 \\
\hline Male sex, \% & 48.2 & 49.6 & 0.961 \\
\hline ICU admission emergent, $\%$ & 90.6 & 76.0 & 0.013 \\
\hline Admission category & & & 0.061 \\
\hline Primary medical, \% & 49.4 & 37.2 & \\
\hline Postop complications/major surgery, \% & 38.8 & 55.4 & \\
\hline Trauma, \% & 11.8 & 7.4 & \\
\hline APACHE II, md (IQR), score & $19.0(10.5)$ & $15.0(10.5)$ & 0.002 \\
\hline ICU stay, md (IQR), days & $6.65(6.34)$ & $2.17(3.43)$ & $<0.0001$ \\
\hline Mechanical ventilation, md (IQR), days & $3.52(5.19)$ & $0.85(2.03)$ & $<0.0001$ \\
\hline \multicolumn{4}{|l|}{ Sedation scores for total ICU stay, } \\
\hline MAAS 0-2, md (IQR), proportion & $0.26(0.30)$ & $0.25(0.24)$ & 0.215 \\
\hline MAAS 3, md (IQR), proportion & $0.65(0.39))$ & $0.71(0.30)$ & 0.135 \\
\hline MAAS 4-6, md (IQR), proportion & $0.04(0.10)$ & $0.00(0.09)$ & 0.041 \\
\hline Prevalence any $4-6, \mathrm{nr}$ of patients $(\%)$ & $52(61.2)$ & $50(41.3)$ & 0.008 \\
\hline Sum, nr of values 4-6 recorded & 310 & 185 & \\
\hline \multicolumn{4}{|l|}{ Receiving any } \\
\hline Propofol , \% & 92.9 & 96.7 & 0.324 \\
\hline Midazolam, \% & 47.1 & 19.8 & $<0.0001$ \\
\hline Ketobemidon*, \% & 91.8 & 81.8 & 0.069 \\
\hline \multicolumn{4}{|l|}{ Average daily dose } \\
\hline Propofol, md (IQR), mg/kg/day & $7.00(16.4)$ & $10.1(16.2)$ & 0.110 \\
\hline Midazolam, md (IQR), mg/kg/day & $0.00(0.18)$ & $0.00(0.00)$ & $<0.0001$ \\
\hline Ketobemidon*, md (IQR), mg/kg/day & $0.23(0.33)$ & $0.24(0.33)$ & 0.170 \\
\hline
\end{tabular}

*An opioid administered in conjunction with propofol and midazolam. 